\title{
Spatiotemporal release of VEGF from biodegradable polylactic-co-glycolic acid microspheres induces angiogenesis in chick chorionic allantoic membrane assay
}

Omar Qutachi ${ }^{\mathrm{a}, *}$

omar.qutachi@dmu.ac.uk

\section{Anthony J. Bullock ${ }^{b}$}

Giuli

Sheila

a Leicester Institute for Pharmaceutical Innovation, Leicester School of Pharmacy, De Montfort University, Leicester, UK

${ }^{\mathbf{b}}$ Department of Materials Science and Engineering, Kroto Research Institute, North Campus, University of Sheffield, Broad Lane, Sheffield S3 7HQ, United Kingdom

${ }^{*}$ Corresponding author at: School of Pharmacy, Faculty of Health and Life Sciences De Montfort University, Leicester LE1 9BH, United Kingdom.

Abstract

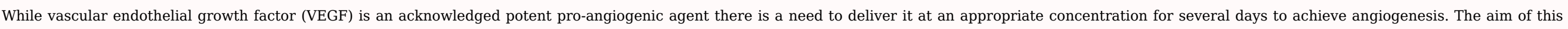

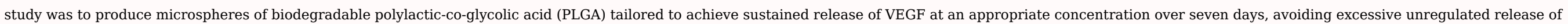

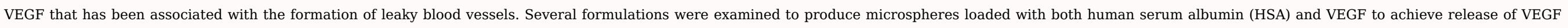

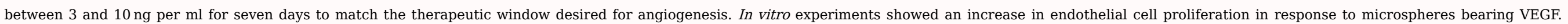

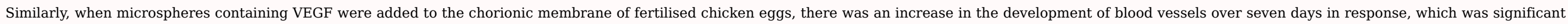

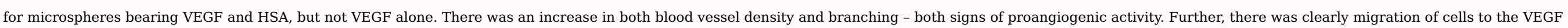

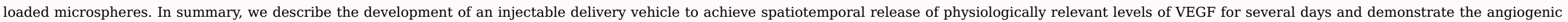
response to this. We propose that such a treatment vehicle would be suitable for the treatment of ischemic tissue or wounds.

Keywords: Chorioallantoic membrane; Vascular endothelial growth factor; Angiogenesis; Polylactic-co-glycolic acid; Sustained release

\section{Introduction}

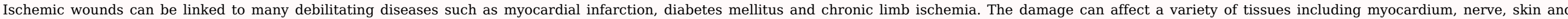

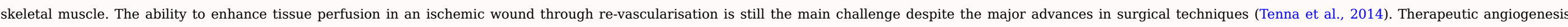

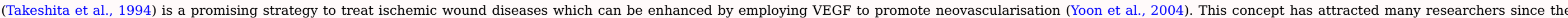

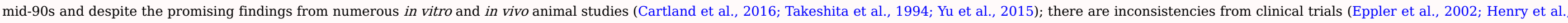

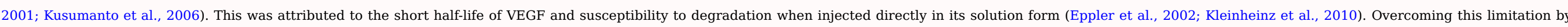

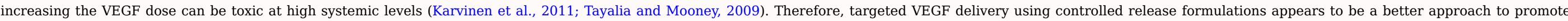

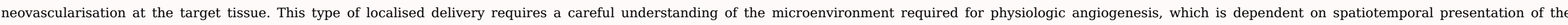
delivered VEGF (Blau and Banfi, 2001)

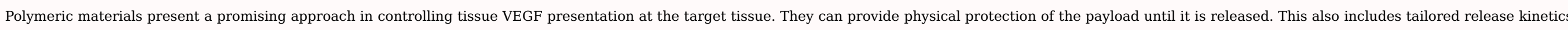

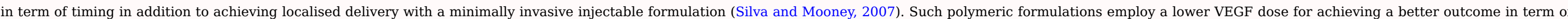




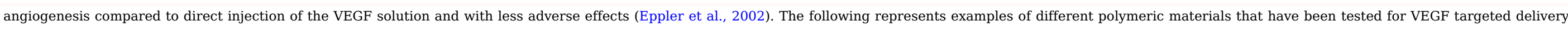
include; fibrin gel (Sacchi et al., 2014), hyaluronic gel (Chen et al., 2012) in addition to PLGA microspheres, nanoparticles or scaffold (des Rieux et al., 2011; Jiang et al., 2015; Yu et al., 2015).

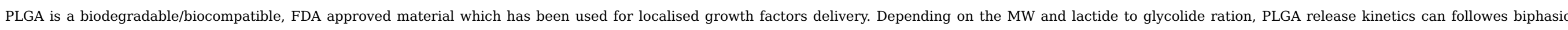

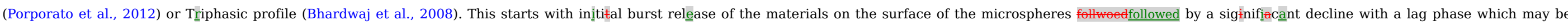

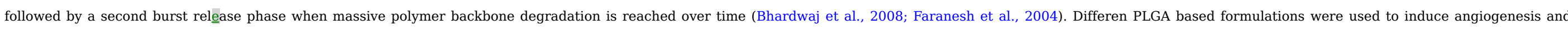

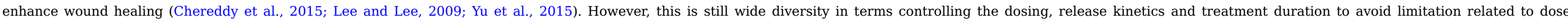
fluctuation or continuous release for unnecessary extended time.

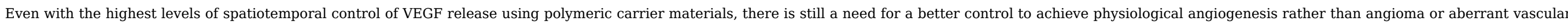

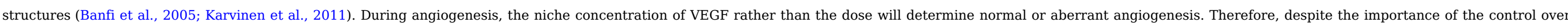

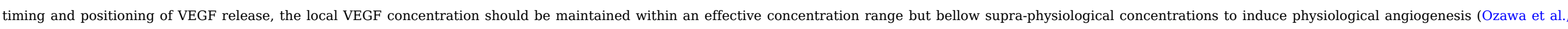
2004).

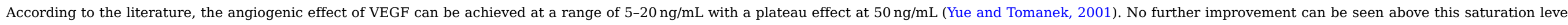

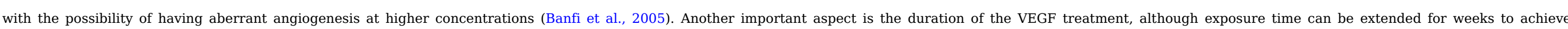

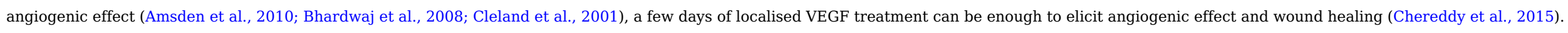

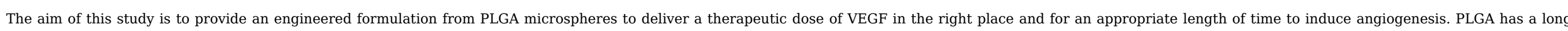

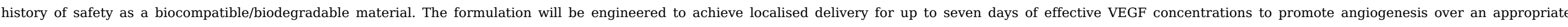

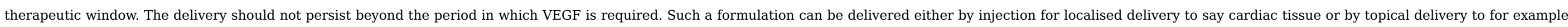
chronic non-healing ulcers.

\section{Materials and methods}

\subsection{Materials}

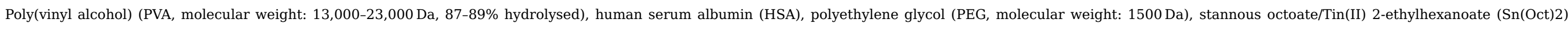

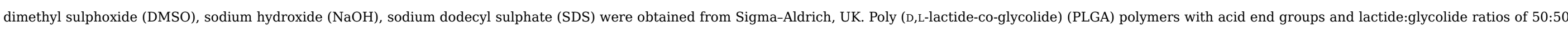

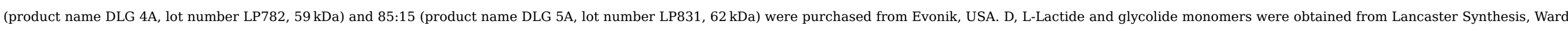

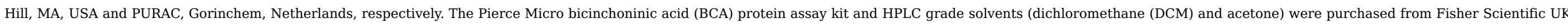
Ltd, Loughborough, UK. Recombinant human VEGF 165 was purchased from Peprotech, UK,

\subsection{Fabrication of microspheres}

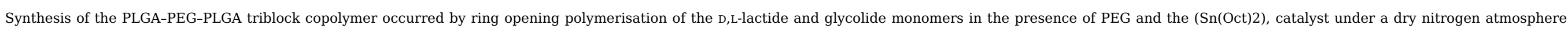

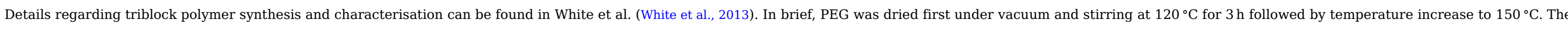

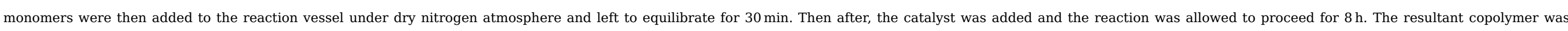

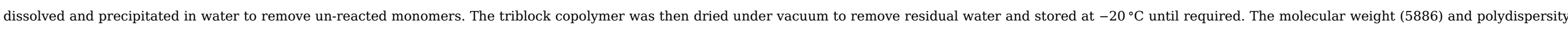

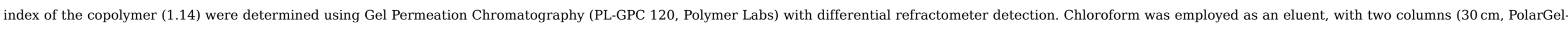
M) in series calibrated against polystyrene standards.

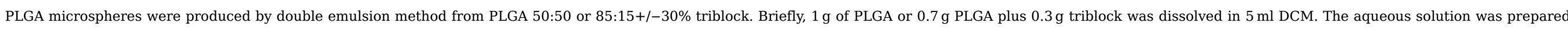

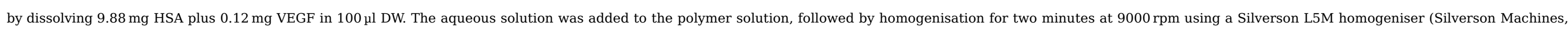




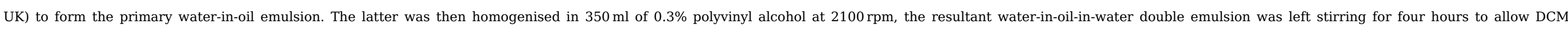

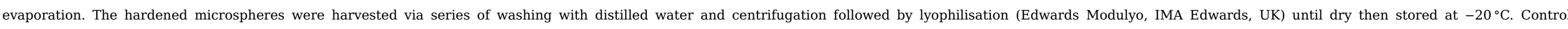

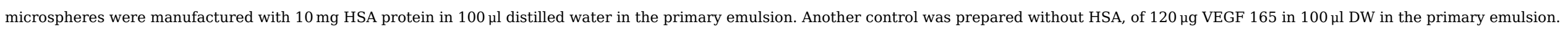

\subsection{Scanning electron microscopy (SEM)}

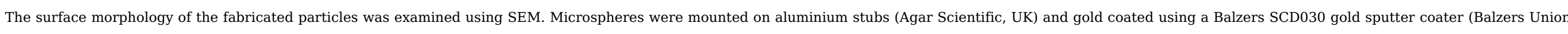

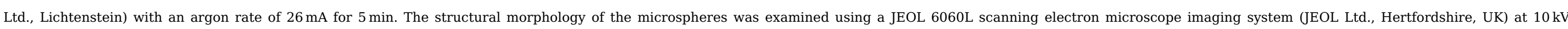
ionising radiation.

\subsection{Microsphere size analysis}

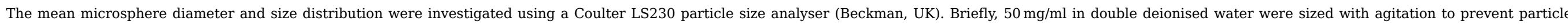
settling. Microsphere size distribution was then determined as a function of the microsphere diffraction and plotted as a function of volume percentage.

\subsection{Entrapment efficiency for total protein}

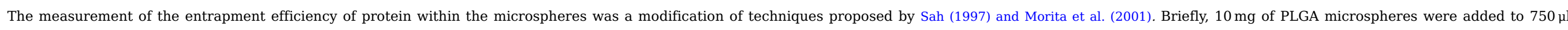

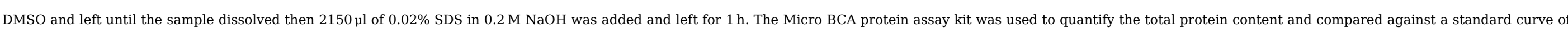
HSA. Sample ( $150 \mu \mathrm{l}$ ) and BCA working reagent (150 $\mathrm{ll}$ ) were mixed and incubated for $2 \mathrm{~h}$ at $37^{\circ} \mathrm{C}$ and the absorbance at $562 \mathrm{~nm}$ measured using a plate reader (Infinite M200, Tecan UK Ltd., Reading, UK).

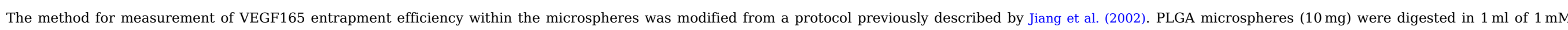

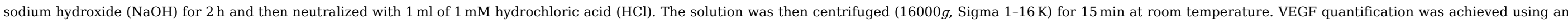

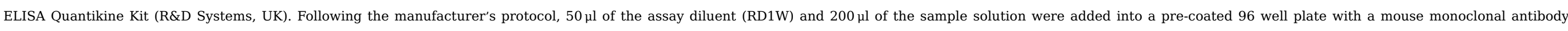

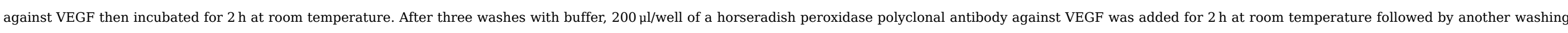

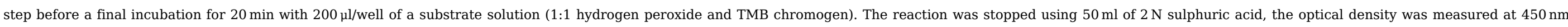
using a plate reader (Infinite M200, Tecan UK Ltd., Reading, UK). VEGF concentrations in the samples were determined using a standard curve of known concentrations of VEGF supplied with the kit.

\subsection{Protein release}

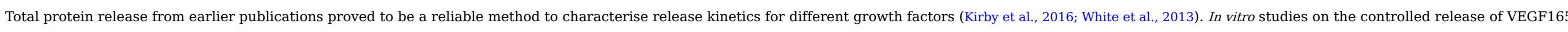

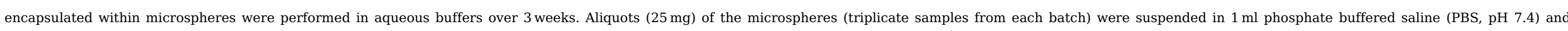

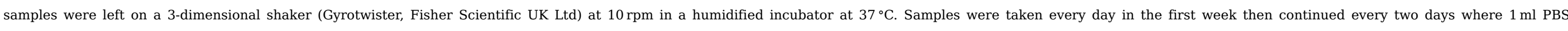

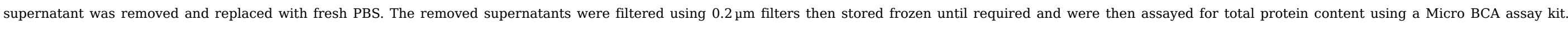
Absorbance values were correlated to a standard curve of HSA in order to determine the total protein content.

\subsection{Proliferation assay}

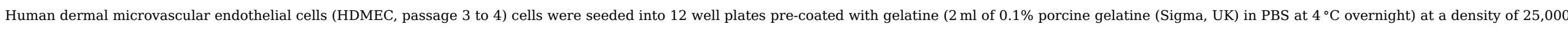

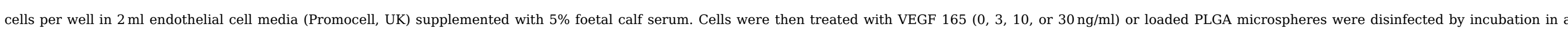

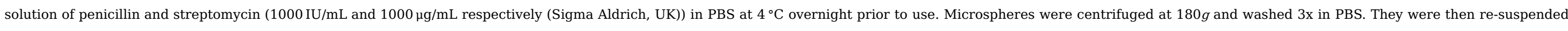

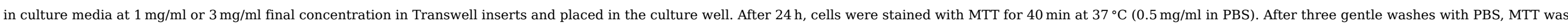
eluted in $200 \mu \mathrm{l}$ of Cellusolve (Sigma, UK).

\subsection{Assessment of proangiogenic properties of PLGA microspheres loaded with VEGF using the CAM assay}




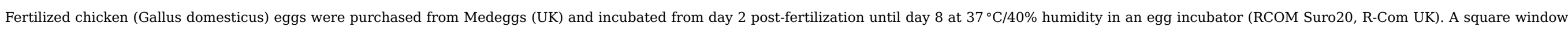

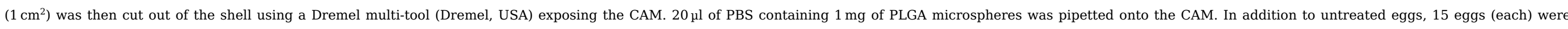

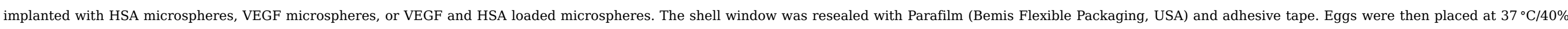

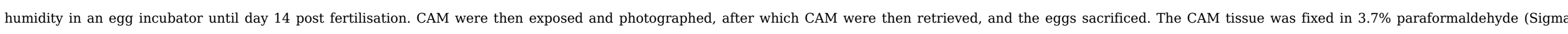

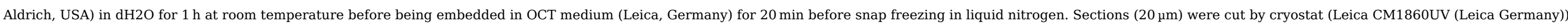

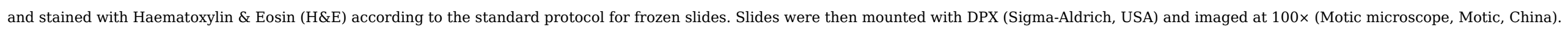

\subsection{Statistics}

All values presented are an average of at least 3 experiments, ANOVA, were used to determine statistical significance, a P value of $<0.05$ was deemed to be significant.

\section{Results}

\subsection{PLGA microsphere characterisation for size, morphology, encapsulation efficiency, and release kinetics}

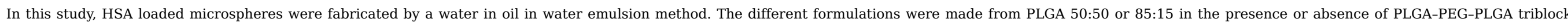

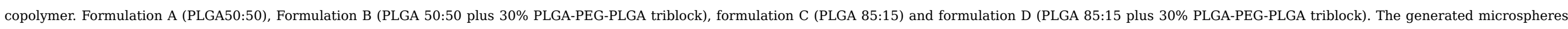

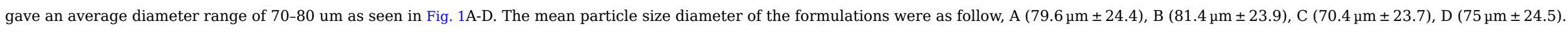
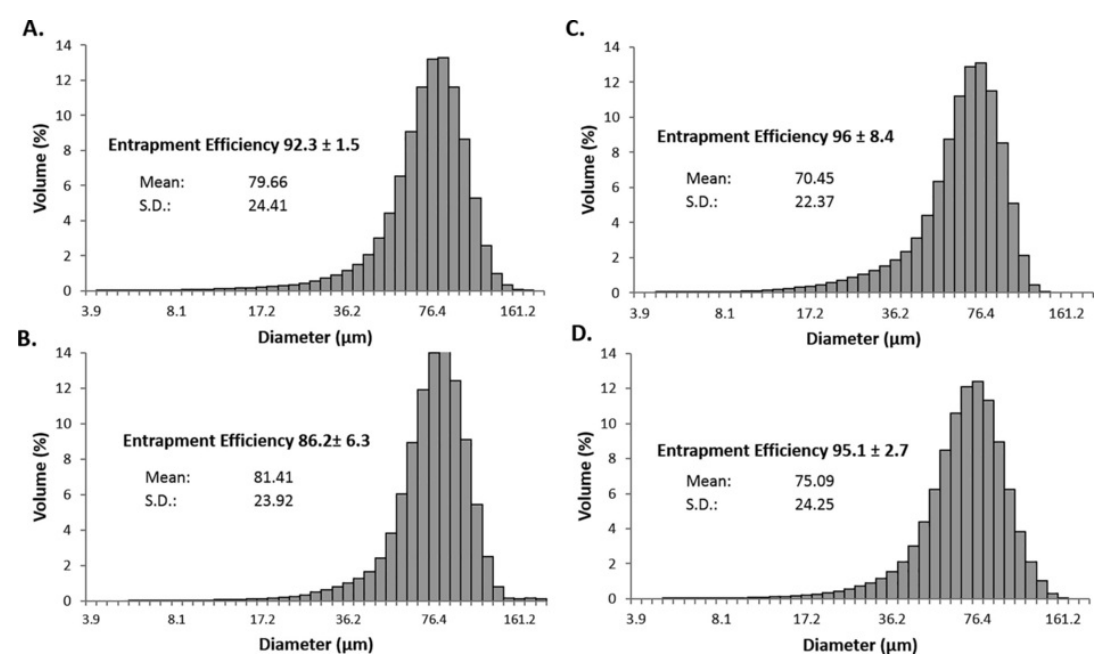

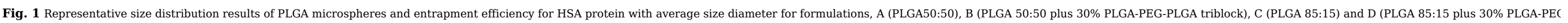
PLGA triblock).

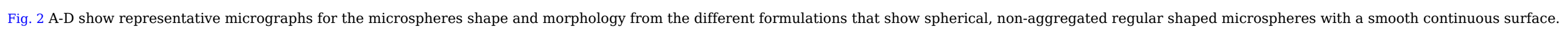



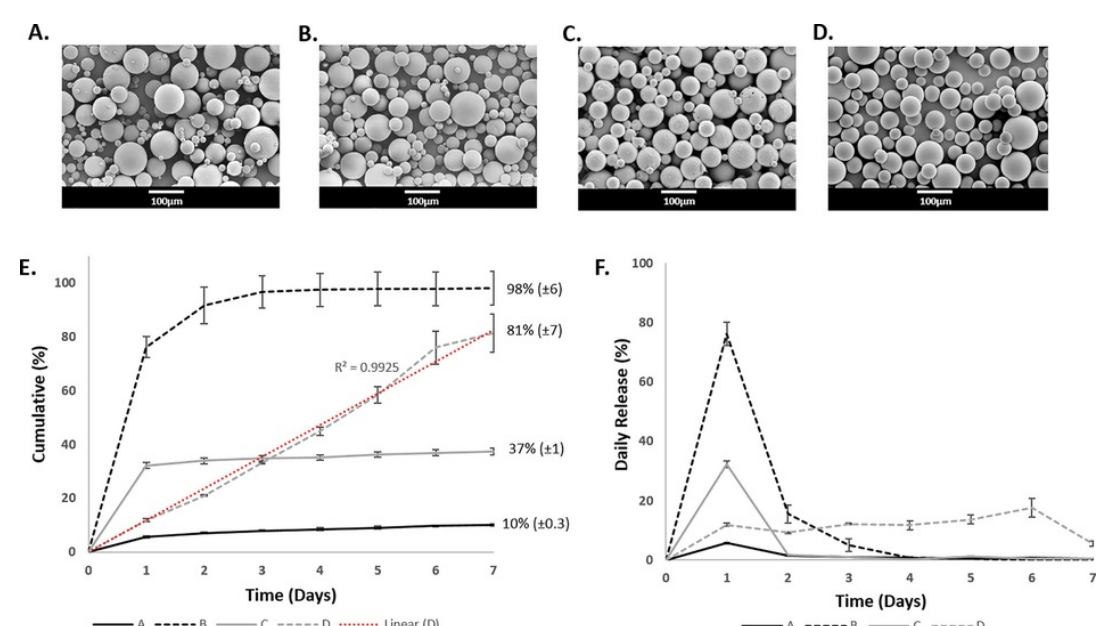

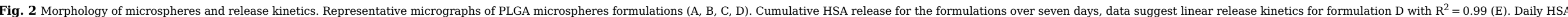
release for formulations over seven day. Results expressed as mean \pm SEM.

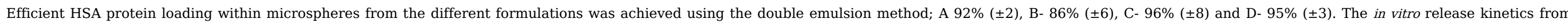

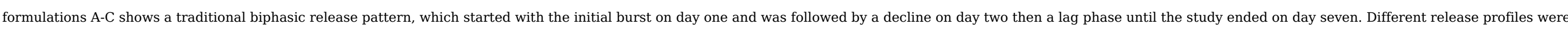

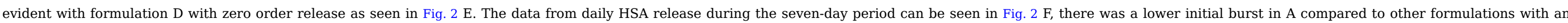

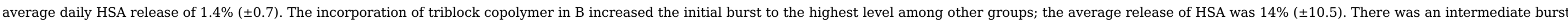

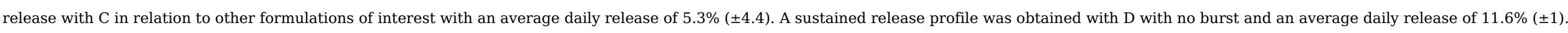

\subsection{VEGF release and bioactivity}

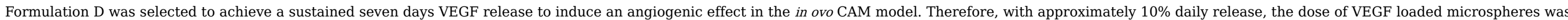
calculated to give the desired release pattern with an effective VEGF concentration of 10-20 ng/mg microspheres/day (Fig. 3).

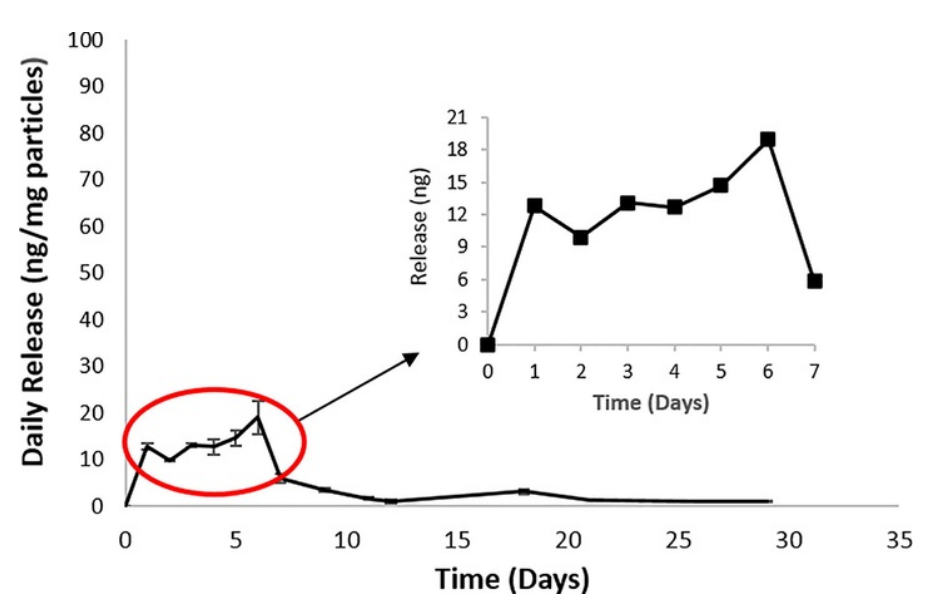

Fig. 3 Daily VEGF release from formulation D (PLGA 85:15 plus 30\% PLGA-PEG-PLGA triblock) based on total protein release over 30 days, with magnified area for the first seven days. Results expressed as mean \pm SEM.

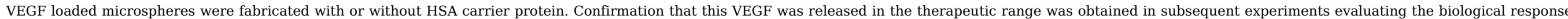




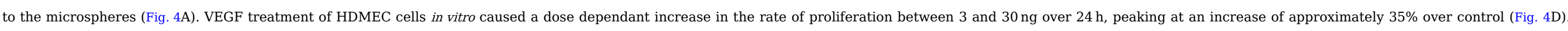

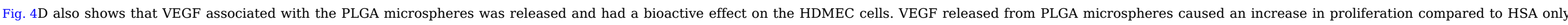

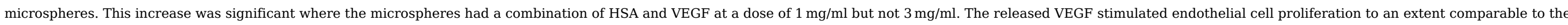
addition of VEGF at a concentration of approximately $5 \mathrm{ng}$ per $\mathrm{ml}$. This was achieved by delivering microspheres in the concentration range of 1-3 mg per ml.

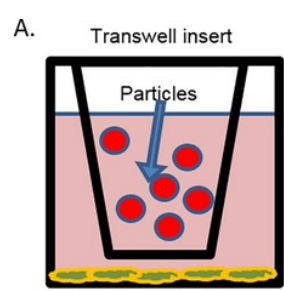

HDMEC seeded on gelatin
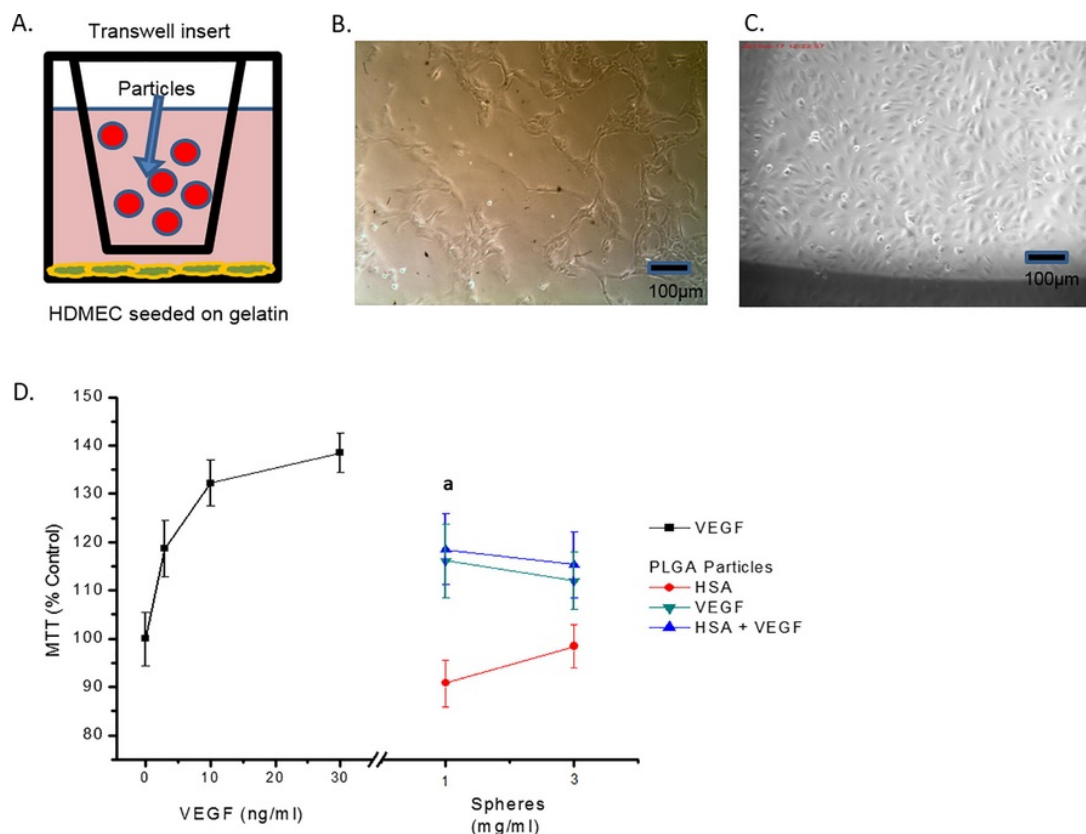

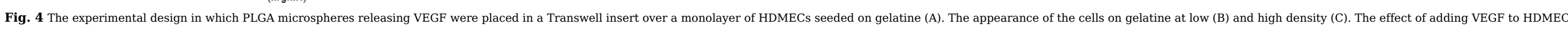

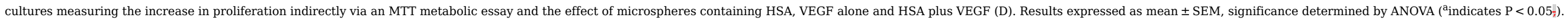

\subsection{Effect of the VEGF releasing microspheres on new blood vessel formation in ovo using the CAM assay}

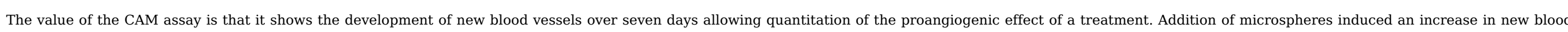
vessel formation, and this was significant when VEGF was delivered with HSA.

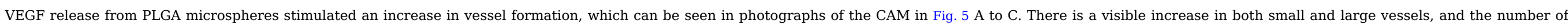

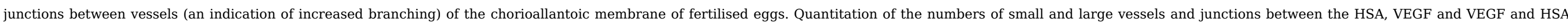

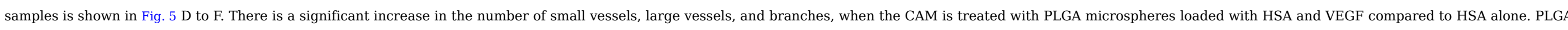

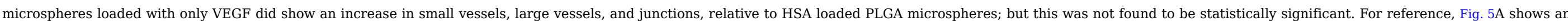
example of the typical large and small vessels and junctions. 

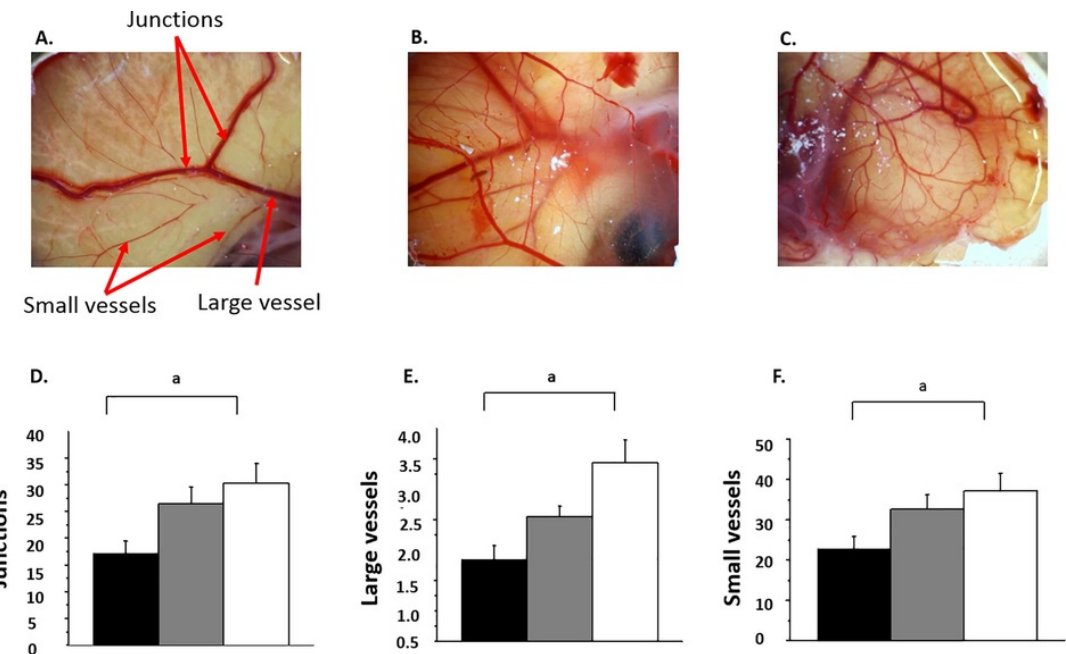

$\square$ HSA $\square$ VEGF $\square$ VEGF+HSA

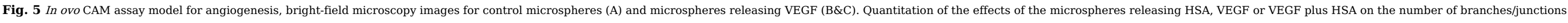
between vessels (D), the number of large vessels (E.) and the small vessels (F). Examples of each type of structure are indicated in (A). Results expressed as mean \pm SEM, significance determined by ANOVA (aindicates $\left.P<0.05_{5}\right)$.

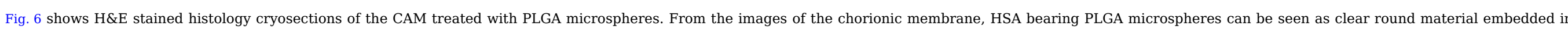

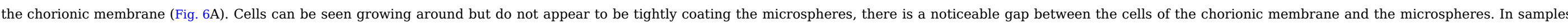

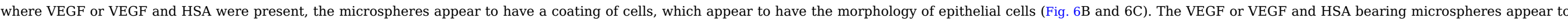
be more tightly surrounded by cells of chorionic membrane than the HSA microspheres; there was no gap in the tissue surrounding the microspheres.

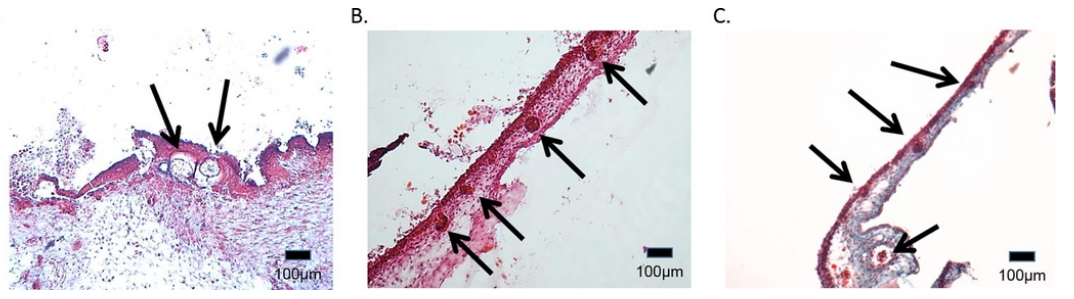

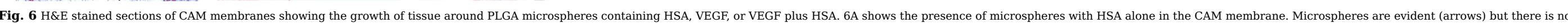
cellular ingrowth into them. 6B shows the ingrowth of cells into microspheres containing VEGF and 6C shows the ingrowth of tissue into microspheres containing VEGF and HSA.

\section{Discussion}

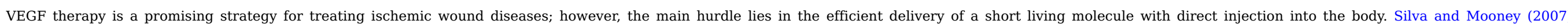

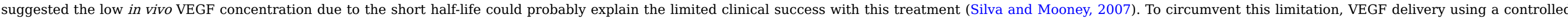

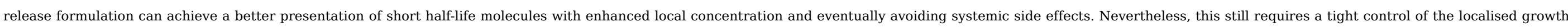

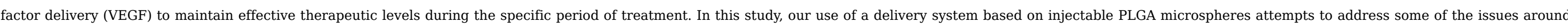

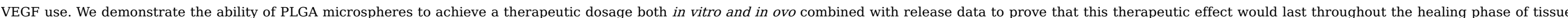

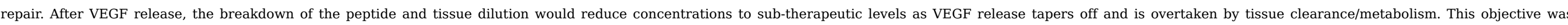

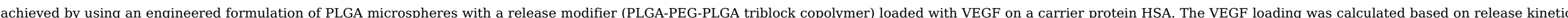




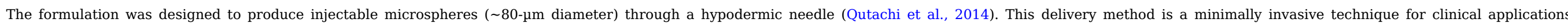

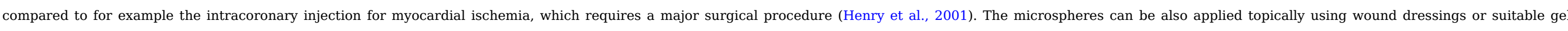

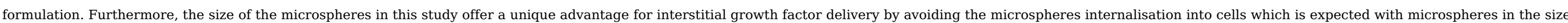
range of 0.1-10 $\mu \mathrm{m}$ (He and Park, 2016).

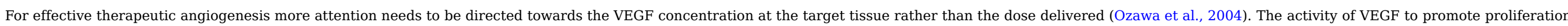

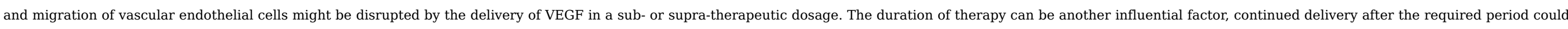

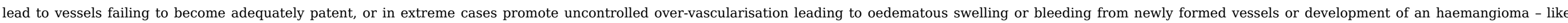

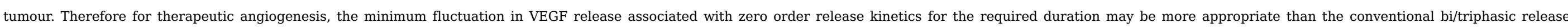
pattern from other PLGA based formulations (Bhardwaj et al., 2008).

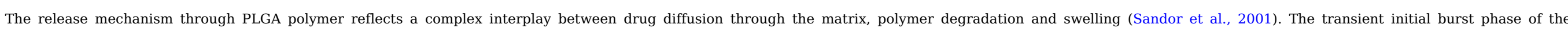

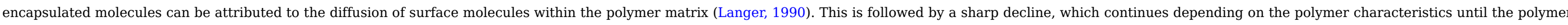

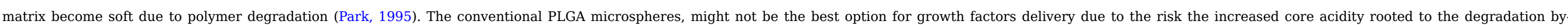

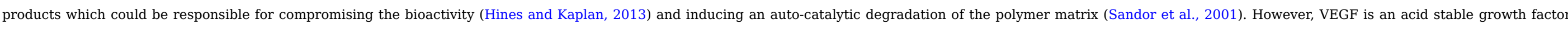

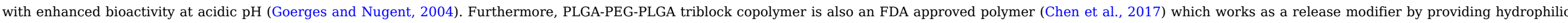

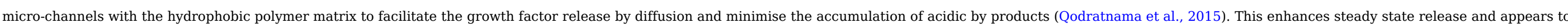
achieve a constant zero order release with PLGA 85:15.

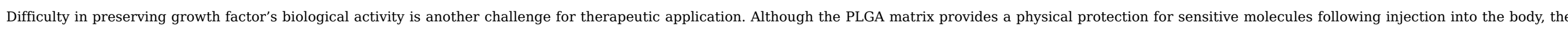

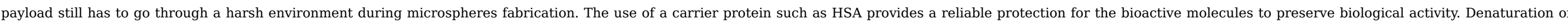

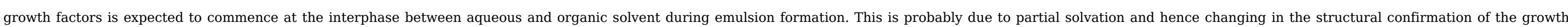
factor molecule. The presence of HSA at high concentration at the interphase will work as shielding agent at the interphase and preserve the growth factor's biological activity (van de Weert et al., 2000).

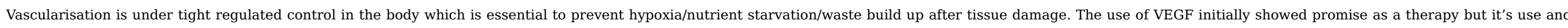

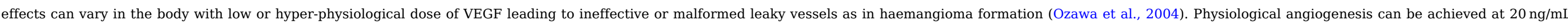

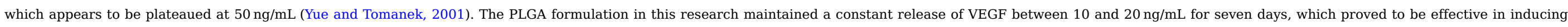
angiogenesis in an in ovo CAM model.

\title{
5 Conclusion
}

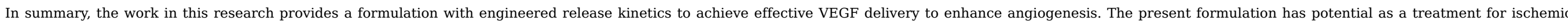

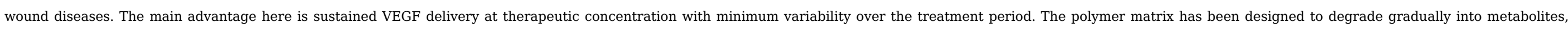
which are readily cleared by the body.

\section{Declaration of interests}

\author{
None.
}

\section{Acknowledgement}

Authors would gratefully acknowledge regenerative medicine platform hub "acellular approaches for therapeutic delivery" (MR/K026682/1) for support.

\section{References}




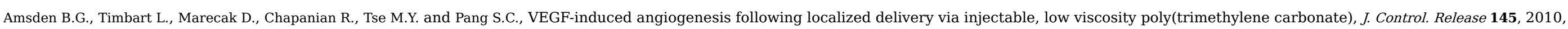
109-115.

Banfi A., von Degenfeld G. and Blau H.M., Critical role of microenvironmental factors in angiogenesis, Curr. Atheroscler. Rep. 7, 2005, $227-234$.

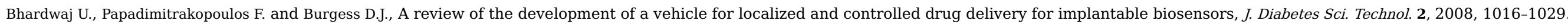

Blau H.M. and Banfi A., The well-tempered vessel, Nat. Med. 7, 2001, 532-534.

Cartland S.P., Genner S.W., Zahoor A. and Kavurma M.M., Comparative evaluation of TRAIL, FGF-2 and VEGF-A-induced angiogenesis in vitro and in vivo, Int. J. Mol. Sci. 17, 2016.

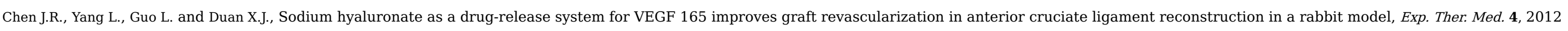
$430-434$.

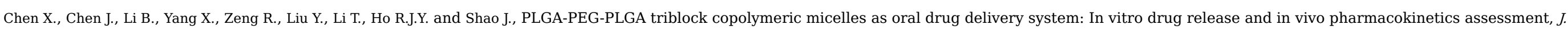
Colloid Interface Sci. 490, 2017, 542-552.

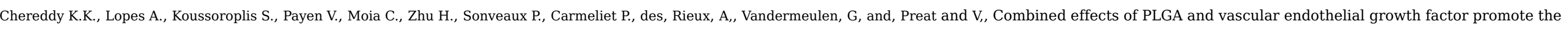
healing of non-diabetic and diabetic wounds, Nanomedicine 11, 2015, 1975-1984.

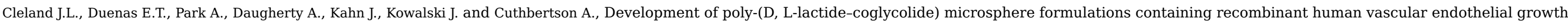
factor to promote local angiogenesis, J. Control. Release 72, 2001, 13-24.

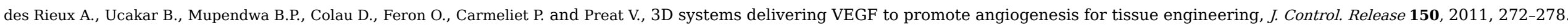

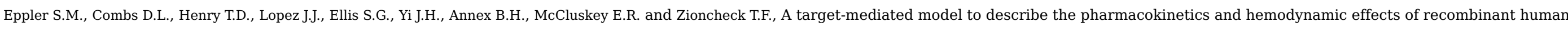
vascular endothelial growth factor in humans, Clin. Pharmacol. Ther. 72, 2002, 20-32.

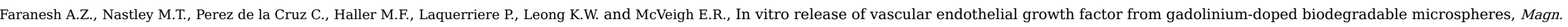
Reson. Med. 51, 2004, 1265-1271.

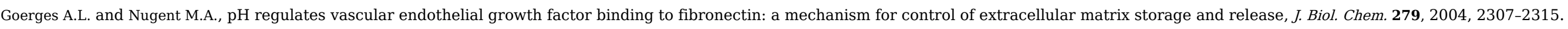

He Y. and Park K., Effects of the microparticle shape on cellular uptake, Mol. Pharm. 13, 2016, 2164-2171.

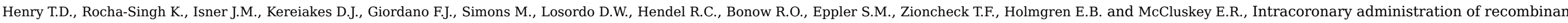
human vascular endothelial growth factor to patients with coronary artery disease, Am. Heart J. 142, 2001, 872-880.

Hines D.J. and Kaplan D.L., Poly(lactic-co-glycolic) acid-controlled-release systems: experimental and modeling insights, Crit. Rev. Ther. Drug Carrier Syst. 30, 2013, 257-276.

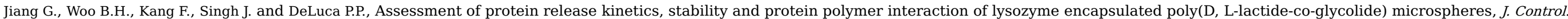
Release 79, 2002, 137-145

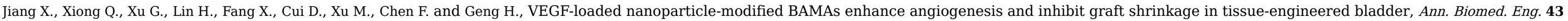
$2015,2577-2586$.

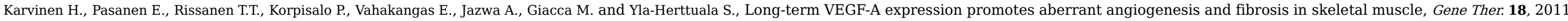
1166-1172. 


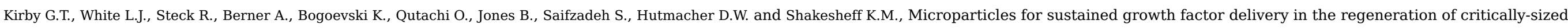
segmental tibial bone defects, Materials 9, 2016, 259.

Kleinheinz J., Jung S., Wermker K., Fischer C. and Joos U., Release kinetics of VEGF165 from a collagen matrix and structural matrix changes in a circulation model, Head Face Med. 6, $2010,17$.

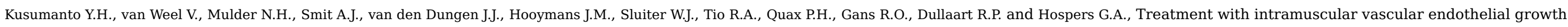
factor gene compared with placebo for patients with diabetes mellitus and critical limb ischemia: a double-blind randomized trial, Hum. Gene Ther. 17, $2006,683-691$.

Langer R., New methods of drug delivery, Science 249, 1990, 1527-1533.

Lee J. and Lee K.Y., Local and sustained vascular endothelial growth factor delivery for angiogenesis using an injectable system, Pharm. Res-Dord. 26, 2009 , 1739-1744.

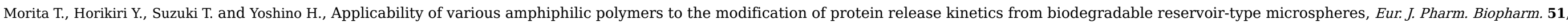
$2001,45-53$.

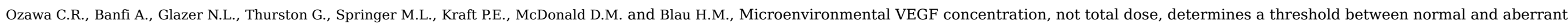
angiogenesis, J. Clin. Invest. 113, 2004, 516-527.

Park T.G., Degradation of poly(lactic-co-glycolic acid) microspheres: effect of copolymer composition, Biomaterials 16, 1995, 1123-1130.

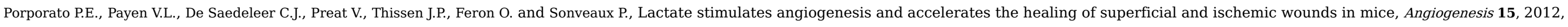
$581-592$.

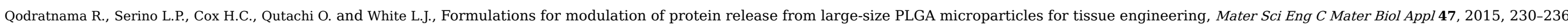

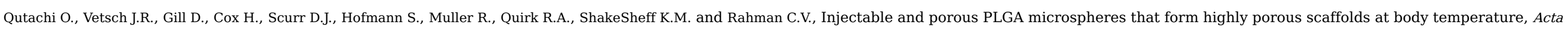
Biomater. 10, 2014, 5090-5098.

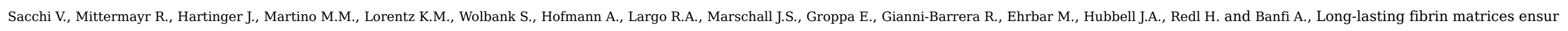
stable and functional angiogenesis by highly tunable, sustained delivery of recombinant VEGF164, Proc. Natl. Acad. Sci. USA 111, $2014,6952-6957$.

Sah H.K., A new strategy to determine the actual protein content of poly(lactide-co-glycolide) microspheres, J. Pharm. Sci. 86, 1997, $1315-1318$.

Sandor M., Enscore D., Weston P. and Mathiowitz E., Effect of protein molecular weight on release from micron-sized PLGA microspheres, J. Control. Release 76, $2001,297-311$.

Silva E.A. and Mooney D.J., Spatiotemporal control of vascular endothelial growth factor delivery from injectable hydrogels enhances angiogenesis, J. Thromb. Haemost. 5, 2007, 590-598.

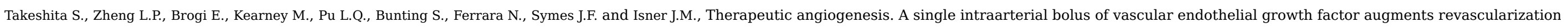
in a rabbit ischemic hind limb model, J. Clin. Invest. 93, 1994, 662-670.

Tayalia P. and Mooney D.J., Controlled growth factor delivery for tissue engineering, Adv. Mater. 21, 2009, 3269-3285.

Tenna A.S., Watson A. and Stansby G., Revascularization for critical limb ischemia in diabetes: surgery or angioplasty?, Angiology 65, 2014, 272-273.

van de Weert M., Hennink W.E. and Jiskoot W., Protein instability in poly(lactic-co-glycolic acid) microparticles, Pharm. Res. 17, $2000,1159-1167$.

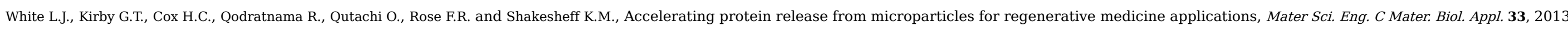
2578-2583.

Yoon Y.S., Johnson I.A., Park J.S., Diaz L. and Losordo D.W., Therapeutic myocardial angiogenesis with vascular endothelial growth factors, Mol. Cell. Biochem. 264, 2004, 63-74. 


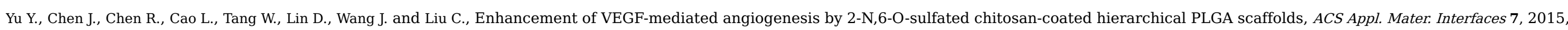
9982-9990.

Yue X. and Tomanek R.J., Effects of VEGF(165) and VEGF(121) on vasculogenesis and angiogenesis in cultured embryonic quail hearts, Am. J. Physiol. Heart Circ. Physiol. 280, 2001, H2240-2247.

\section{Graphical abstract}

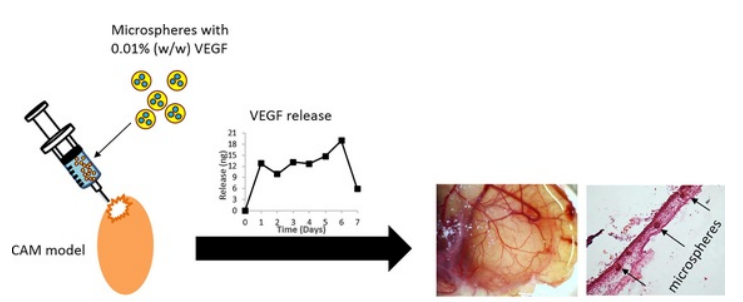

Injection Incubation $\left(7\right.$ days $\left.33^{\circ} 37^{\circ}\right)$

Enhanced Angiogenesis

\section{Queries and Answers}

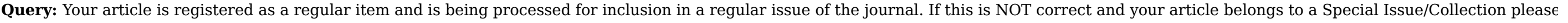
contact j.paulinj@elsevier.com immediately prior to returning your corrections.

Answer: Yes

Query: The author names have been tagged as given names and surnames (surnames are highlighted in teal color). Please confirm if they have been identified correctly

Answer: Yes

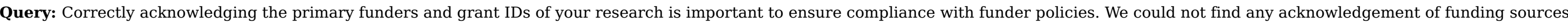
in your text. Is this correct? /

Answer: Yes 